\title{
Reaction of acetophenone and benzylphenylketone oximes with phenylacetylene: a route to di- and triphenylpyrroles
}

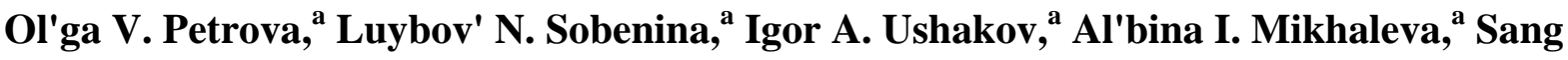 \\ Heon Hyun, and Boris A. Trofimov*,a
}

${ }^{a}$ A. E. Favorsky Irkutsk Institute of Chemistry, Siberian Branch of the Russian Academy of Sciences, 1 Favorsky St., Irkutsk 664033, Russian Federation

${ }^{b}$ Samsung Advanced Institute of Technology, Display Device \& Material Lab. San 14-1, Nongseo-Dong, Giheung-Gu, Yongin, Gyeonggi-Do 446-712, Korea

E-mail: boris_trofimov@irioch.irk.ru; romeos.hyun@samsung.com

This paper is dedicated to Professor Alexander Pozharskii on the occasion of his 70th anniversary

\begin{abstract}
The reaction of oximes of aromatic ketones with phenylacetylene in the presence of superbase systems ( $\mathrm{MOH}-\mathrm{DMSO}$, where $\mathrm{M}=\mathrm{Li}, \mathrm{Na}, \mathrm{K}$ ) has been extensively studied for the first time. The effects of alkaline metal cation, the ketoximes structure and the reaction conditions (temperature, duration) on the products composition have been evaluated. Acetophenone oxime reacts with phenylacetylene ( $\mathrm{MOH}-\mathrm{DMSO}$, where $\mathrm{M}=\mathrm{Li}, \mathrm{Na}, \mathrm{K}, 140{ }^{\circ} \mathrm{C}, 6 \mathrm{~h}$ ) to afford 2,5diphenyl-1H-pyrrole in 14-18\% isolated yield. The reaction of benzylphenylketoxime with phenylacetylene ( $\mathrm{LiOH}-\mathrm{DMSO}, 120{ }^{\circ} \mathrm{C}, 12 \mathrm{~h}$ ) delivers 2,3,4-, 2,3,5-triphenyl-1H-pyrroles (in $17 \%$ total yield) and 2,3,4-triphenyl-1-[(Z)-2-phenylethenyl]-1 $H$-pyrrole (7\% yield).
\end{abstract}

Keywords: Acetophenone oxime, benzylphenylketoxime, phenylacetylene, 2,5-diphenyl-1Hpyrrole, 2,3,4- and 2,3,5-triphenyl-1H-pyrroles

\section{Introduction}

A number of natural and synthetic pyrroles bearing aryl substituents possess high biological activity. ${ }^{1,2}$ Currently, certain of the di- and triarylpyrroles are extensively employed as pharmaceuticals. For example, the cholesterol reduction drug lipitor (atorvastatin), one of the most commonly used in the United States, contains a 2,3-diphenylpyrrole motif. ${ }^{2 a, 3}$ A series of 2,3,4-triphenylpyrrole derivatives exert high hypoglycemic action and can be recommended for diabetes treatment. ${ }^{2 a}$ Although arylpyrroles are applied for the synthesis of fluorescent azaindacene dyes of BODIPY family ${ }^{4}$ as well as optoelectronic materials, ${ }^{5}$ it is their 
pharmacological appeal that seems to be the chief reason for a steady interest in the development of synthetic procedures for these compounds, reported, in particular, in reviews. ${ }^{1,2}$

Di- and triphenylpyrroles are normally prepared by condensation of 1,4-diketones with ammonia or ammonium acetate, ${ }^{6-9}$ as well as by the reaction of 1,3 -diketones ${ }^{10,11}$ with different nitrogen-containing compounds (ammonium acetate, aromatic imines, oximes) followed by cyclization of the intermediates formed. Despite the satisfactory yields of the target products, the syntheses reported feature either hard availability of the starting materials ${ }^{12}$ or multi-step procedures. $^{10}$

The reaction of ketoximes with acetylene (the Trofimov reaction) in the superbase systems MOH-DMSO, where $\mathrm{M}=\mathrm{Li}, \mathrm{Na}, \mathrm{K}$, makes it possible to prepare a wide series of substituted pyrroles in one preparative step. ${ }^{1,13}$ While this reaction is mostly studied with unsubstituted acetylene the applicability of phenylacetylene, an available substituted acetylene, still remains poorly understood. ${ }^{14}$ Meanwhile, the reaction of oximes of aromatic ketones with phenylacetylene could open a short-cut to pyrroles with several aromatic substituents.

In this work, using the examples of oximes of acetophenone $\mathbf{1}$ and benzylphenylketone 2 with phenylacetylene 3 , we have undertaken a more thorough study of the reaction to gain a clearer understanding of the effect of the alkaline metal cation in the catalyzing systems as well as the influence of the ketoxime structure and reaction conditions on the ratio and yields of the reaction products. Apart from extension of the basic knowledge about the scope and limitations of the pyrrole synthesis from ketoximes and acetylenes it was hoped to elaborate one-step preparative protocols for the synthesis of as yet hardly accessible di- and triphenylpyrroles.

\section{Results and Discussion}

The experiments have shown that at $140{ }^{\circ} \mathrm{C}(6 \mathrm{~h})$ in the MOH-DMSO ketoxime 1 gave with phenylacetylene the expected 2,5-diphenyl-1H-pyrrole (4) in 14-18\% isolated yield along with starting acetophenone 5 (yield up to 35-55\%) and tar (mostly unidentified products of the basecatalyzed phenylacetylene condensation), ${ }^{15,16}$ the conversion of ketoxime 1 ranging from 69 to $80 \%$ (depending on the alkaline metal cation nature) (Scheme 1).

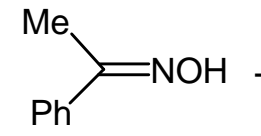

1

$\mathrm{M}=\mathrm{Li}, \mathrm{Na}, \mathrm{K}$

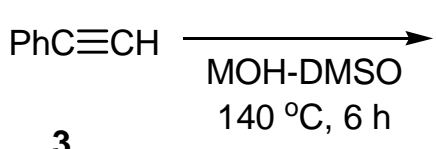

3

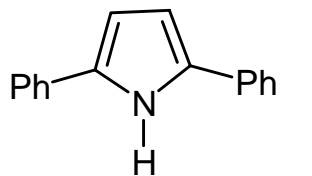

4

$14-18 \%$

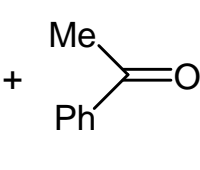

5

up to $35-55 \%$

\section{Scheme 1}


The highest conversion of $\mathbf{1}(80 \%)$ was observed in the case of $\mathrm{NaOH}$ whereas those for $\mathrm{LiOH}$ and $\mathrm{KOH}$ were 77 and 69\%, respectively. At the same time the yield of the target pyrrole 4 was not practically affected by the $\mathrm{MOH}$ nature, being somewhat higher for $\mathrm{KOH}(18 \%)$. Meanwhile, with $\mathrm{LiOH}$ the isolation of pyrrole $\mathbf{4}$ was found to be easier owing to a lesser amount of persistent side products formed. Therefore, it is $\mathrm{LiOH}$ that can be recommended for use in a preparative protocol for synthesis of pyrrole 4 (yield 17\%).

The peculiarity of this reaction as compared with those using unsubstituted acetylene is the prevailing of deoximation (formation of ketone 5) over the heterocyclization to pyrrole 4 . In fact, it means that the recovered starting ketone 5 can be returned (recycled) to the same reaction again (via ketoxime $\mathbf{1}$ which can be quantitatively prepared from the ketone and hydroxylamine). Consequently, the yield of pyrrole 4 when calculated on the initial ketone 5 consumed, is about two times higher that isolated one (even not accounting for the incomplete conversion of oxime 1).

Thus, having in mind availability of the starting materials and the straightforward one-pot synthetic procedure, the reaction of acetophenone oxime with phenylacetylene may be considered as acceptable for the preparation of 2,5-diphenyl-1H-pyrrole (4) despite the modest yield.

Under analogous conditions (LiOH-DMSO, $140 \quad{ }^{\circ} \mathrm{C}, 6 \mathrm{~h}$ ), the reaction of benzylphenylketoxime (2) with acetylene 3 delivers 2,3,4-triphenyl- (6), 2,3,5-triphenyl-1Hpyrroles (7) and 2,3,4-triphenyl-1-[(Z)-2-phenylethenyl]-1H-pyrrole (8) (their content in the crude product is 37,24 and $30 \%$, respectively), the conversion of oxime 2 being almost complete $(90 \%)$ (Scheme 2).

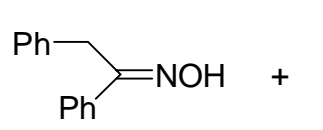

2

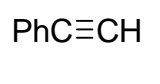

3

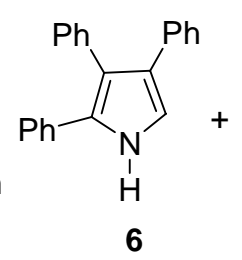

6

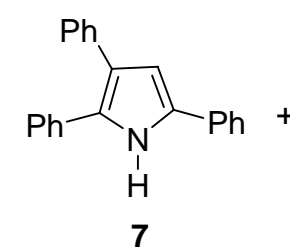

7

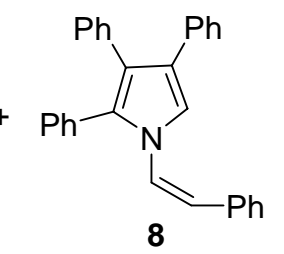

\section{Scheme 2}

The pyrrole 8 is a product of further regio- and stereoselective vinylation of pyrrole $\mathbf{6}$ with phenylacetylene. Noteworthy that other isomeric pyrrole 7 is not vinylated under these conditions, obviously due to the steric hindrance imposed by phenyl substituents in the position 5 of the pyrrole ring. Since the vinylpyrrole 8 can be easily separated from the mixture of pyrroles 6 and 7 (see experimental), there is an opportunity to isolate pure pyrrole 7 by using excess phenylacetylene and carrying out the reaction up to completed vinylation of pyrrole $\mathbf{6}$. Another interesting feature of this reaction is that the expected deoximation product, phenylbenzylketone was detected in the reaction mixture in negligible quantities $(2 \%)$ only. At a lower temperature 
$\left(120^{\circ} \mathrm{C}\right)$ and dropwise feeding of phenylacetylene, the content of the vinylated pyrrole 8 in the reaction mixture decreased to 9\%, and those of 2,3,4-triphenyl- (6) and 2,3,5-triphenylpyrroles (7) correspondingly dropped (31 and 13\%). In this case, the crude product contained $44 \%$ of starting oxime 2 (Table 1).

The ${ }^{1} \mathrm{H}$ NMR monitoring of the reaction of benzylphenylketoxime (2) with phenylacetylene $\left(\mathrm{LiOH}-\mathrm{DMSO}, 120^{\circ} \mathrm{C}\right)$ indicates that the pyrrole $\mathbf{6}$ is formed first, i.e. at a higher rate than the pyrrole 7 (Table 1).

Table 1. ${ }^{1} \mathrm{H}$ NMR monitoring of the reaction of benzylphenylketoxime (2) with phenylacetylene $\left(\mathrm{LiOH}-\mathrm{DMSO}, 120{ }^{\circ} \mathrm{C}\right)$

\begin{tabular}{cccccc}
\hline & \multicolumn{5}{c}{ Content of the reaction mixture, \% $\left({ }^{1} \mathrm{H}\right.$ NMR $)$} \\
\cline { 2 - 6 } Time, h & $\begin{array}{c}\text { Benzyl- } \\
\text { phenylketone }\end{array}$ & Oxime 2 & Pyrrole 6 & Pyrrole 7 & Pyrrole 8 \\
\hline 1 & 2 & 92 & 5 & 1 & 0 \\
2 & 2 & 83 & 12 & 3 & 0 \\
3 & 2 & 74 & 17 & 5 & 2 \\
4 & 3 & 62 & 22 & 9 & 4 \\
5 & 3 & 50 & 29 & 11 & 7 \\
6 & 3 & 44 & 31 & 13 & 9 \\
\hline
\end{tabular}

From the data of Table 1, it may be assumed that the selective preparation of pyrrole 6 is achievable. Indeed, when the reaction was stopped at $20 \%$ conversion of oxime 2 , the ratio of pyrroles 6 and 7 was 4:1.

The formation of two isomeric triphenylpyrroles 6 and 7 may be rationalized by cyclization (via [3,3]-sigmatropic rearrangement) of isomeric $O$-vinylketoximes 9 and 10, the primary adducts of oxime 2 to acetylene 3 (Scheme 3).

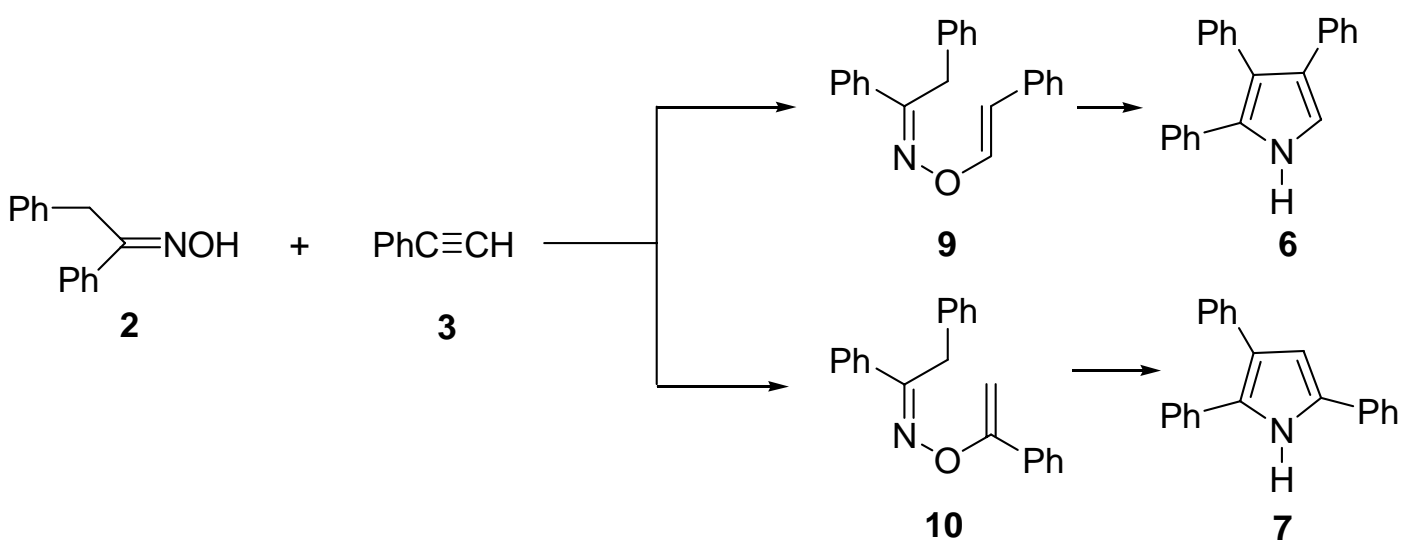

\section{Scheme 3}


Such a mechanism was experimentally proved in a number of previous works ${ }^{4,13 f, 17}$ where the similar intermediate $O$-vinyloximes were isolated and separately rearranged to the corresponding pyrroles.

In summary, the reaction of oximes of aromatic ketones with phenylacetylene in $\mathrm{MOH}$ DMSO systems paves a new path to one-pot preparation of di- and triarylpyrroles - promising precursors of pharmaceutically important compounds and optoelectronic materials.

\section{Experimental Section}

General Procedures. IR spectra were recorded from $\mathrm{KBr}$ pellets on a Bruker IFS-25 instrument. NMR spectra were run on a Bruker DPX 400 spectrometer $\left[400.13\left({ }^{1} \mathrm{H}\right) \mathrm{MHz}, 100.6 \mathrm{MHz}\right.$ $\left.\left({ }^{13} \mathrm{C}\right)\right]$; $\mathrm{CDCl}_{3}$ as solvent, HMDS as internal standard. Detailed ${ }^{13} \mathrm{C}$ NMR peak assignments were obtained by careful analysis of HSQC and HMBC 2D NMR spectra. GCMS spectrum was run on a MSD5975C (Agilent), microanalyses were obtained in the A.E. Favorsky Irkutsk Institute of Chemistry, Siberian Branch of the Russian Academy of Sciences, Russia on an EA FLASH 1112 Series (CHN Analyzer) instrument.

2,5-Diphenyl-1H-pyrrole (4). The oxime 1 (20.41 g, $0.151 \mathrm{~mol}$ ) and $\mathrm{LiOH}$ (3.61 g, $0.151 \mathrm{~mol}$ ) were dissolved under stirring and heating $\left(100-110{ }^{\circ} \mathrm{C}, 3 \mathrm{~h}\right)$ in DMSO $(150 \mathrm{ml})$. Phenylacetylene $(16.85 \mathrm{~g}, 0.165 \mathrm{~mol})$ was added to the formed lithium oximate solution, temperature of the mixture was raised to $137-140{ }^{\circ} \mathrm{C}$ and the reaction mixture was stirred during $6 \mathrm{~h}$. After cooling up to room temperature the reaction mixture was diluted with water and extracted with diethyl ether $(50 \mathrm{ml} \times 5)$. The ether extracts were washed with water $(50 \mathrm{ml}$ x 3$)$ and dried over $\mathrm{K}_{2} \mathrm{CO}_{3}$. The residue after removal of diethyl ether was distillated in vacuo (2 $\mathrm{mm} \mathrm{Hg}$ ) to remove acetophenone formed $(9.94 \mathrm{~g}, 55 \%)$ and then rectified in fine vacuo $\left(6 \cdot 10^{-2} \mathrm{~mm} \mathrm{Hg}\right)$ to give 4.70 $\mathrm{g}$ of unreacted oxime 1 (77\% conversion) and $7.40 \mathrm{~g}$ of a fraction containing pyrrole $\mathbf{4}$ and side products $\left({ }^{1} \mathrm{H} \mathrm{NMR}\right)$. Recryctallization of this fraction from heptene afforded $5.59 \mathrm{~g}(17 \%)$ of 2,5-diphenyl-1 $H$-pyrrole (4), beige crystals, m.p. 141-142 ${ }^{\circ} \mathrm{C}\left[\right.$ ref. $\left.^{14} 142{ }^{\circ} \mathrm{C}\right] ;{ }^{1} \mathrm{H}$ NMR $\delta 8.58$ (br $\mathrm{s}, 1 \mathrm{H}, \mathrm{NH}), 7.45\left(\mathrm{~m}, 4 \mathrm{H}, \mathrm{H}_{o}\right), 7.30\left(\mathrm{~m}, 4 \mathrm{H}, \mathrm{H}_{m}\right), 7.18\left(\mathrm{~m}, 2 \mathrm{H}, \mathrm{H}_{p}\right), 6.57\left(\mathrm{~d},{ }^{4} J=2.5 \mathrm{~Hz}, 2 \mathrm{H}, \mathrm{H}-3\right.$, $\mathrm{H}-4) ;{ }^{13} \mathrm{C}$ NMR $\delta 133.2(\mathrm{C}-2, \mathrm{C}-5), 132.6\left(\mathrm{C}_{i}\right), 129.0\left(\mathrm{C}_{m}\right), 126.2\left(\mathrm{C}_{p}\right), 123.9\left(\mathrm{C}_{o}\right), 108.0(\mathrm{C}-3, \mathrm{C}-$ 4); IR v 3457, 3058, 3022, 1943, 1868, 1803, 1735, 1605, 1579, 1486, 1459, 1380, 1333, 1314, 1275, 1186, 1156, 1076, 1052, 1028, 903, 783, 753, 691, 665, $510 \mathrm{~cm}^{-1}$. Anal. Calcd. for $\mathrm{C}_{16} \mathrm{H}_{13} \mathrm{~N}$ : C, 87.64; H, 5.98; N, 6.38. Found: C, 87.86; H, 5.92; N, 6.20.

Analogously from oxime 1 (20.41 g, $0.151 \mathrm{~mol}), \mathrm{NaOH}(6.04 \mathrm{~g}, 0.151 \mathrm{~mol})$, phenylacetylene (16.85 g, $0.165 \mathrm{~mol})$ (150 ml DMSO, $137-140{ }^{\circ} \mathrm{C}, 6 \mathrm{~h}$ ) was prepared $4.73 \mathrm{~g}$ (14\%) of pyrrole 4 , the oxime conversion was $80 \%$.

Analogously from oxime 1 (20.41 g, $0.151 \mathrm{~mol}), \mathrm{KOH}(8.47 \mathrm{~g}, 0.151 \mathrm{~mol})$, phenylacetylene (16.85 g, $0.165 \mathrm{~mol})\left(150 \mathrm{ml}\right.$ DMSO, $137-140{ }^{\circ} \mathrm{C}, 6 \mathrm{~h}$ ) was prepared $5.92 \mathrm{~g}$ (18\%) of pyrrole 4, the oxime conversion was $69 \%$. 
2,3,4-Triphenyl-1H-pyrrole (6), 2,3,5-triphenyl-1H-pyrrole (7) and 2,3,4-triphenyl-1-[(E)-2phenylethenyl]-1H-pyrrole (8). A mixture of benzylphenylketoxime 2 (5.0 g, $0.024 \mathrm{~mol})$ and $\mathrm{LiOH}(0.57 \mathrm{~g}, 0.024 \mathrm{~mol})$ in $\mathrm{DMSO}(50 \mathrm{ml})$ was stirred at $95-100{ }^{\circ} \mathrm{C}$ for $2 \mathrm{~h}$ to give the corresponding oximate. Then a solution of phenylacetylene $(2.66 \mathrm{~g}, 0.026 \mathrm{~mol})$ in DMSO $(25$ $\mathrm{ml}$ ) was added to the reaction mixture at $120{ }^{\circ} \mathrm{C}$ for $8 \mathrm{~h}$ and heated for another $4 \mathrm{~h}$. After cooling to room temperature the reaction mixture was diluted with water, extracted with diethyl ether (30 $\mathrm{ml} \times 5)$. The extract were washed with water and dried over $\mathrm{K}_{2} \mathrm{CO}_{3}$. The diethyl ether was removed to afford $6.73 \mathrm{~g}$ of mixture containing 39\% of 2,3,4-triphenyl-1H-pyrrole (6), 30\% of the oxime 2, $15 \%$ of 2,3,4-triphenyl-1-[(Z)-2-phenylethenyl]- $1 H$-pyrrole (8), 14\% of 2,3,5triphenyl- $1 H$-pyrrole (7) and $2 \%$ of benzylphenylketone ( ${ }^{1} \mathrm{H}$ NMR). The mixture obtained was dissolved in hot ethanol, the latter was cooled and the fine light-yellowish crystals precipitated were filtered off and dried to give $0.69 \mathrm{~g}$ (7\%) of 2,3,4-triphenyl-1-[(Z)-2-phenylethenyl]-1Hpyrrole (8). Ethanol was removed from the filtrate and the residue was separated by preparative TLC $\left(\mathrm{Al}_{2} \mathrm{O}_{3}\right.$, eluent - hexane : ethylacetate, 10:1) to obtain $1.21 \mathrm{~g}$ (17\%) of 2,3,4-triphenyl- (6) and 2,3,5-triphenyl-1H-pyrroles (7) mixture (ratio of $6: 7$ was $7: 3,{ }^{1} \mathrm{H} \mathrm{NMR}$ ), $1.51 \mathrm{~g}$ of the starting oxime 2 (70\% conversion). The yield of 2,3,4-triphenyl- and 2,3,5-triphenyl-1H-pyrroles mixture was $25 \%$ with respect to the benzylphenylketoxime reacted.

2,3,4-Triphenyl-1H-pyrrole (6) and 2,3,5-triphenyl-1H-pyrrole (7). IR v 3441, 3358, 3060, 3026, 1951, 1883, 1811, 1680, 1600, 1505, 1488, 1450, 1392, 1340, 1317, 1273, 1216, 1177 , 1157, 1072, 1028, 957, 912, 903, 758, 698, 668, 623, $507 \mathrm{~cm}^{-1}$. MS $m / z\left(J_{\text {rel. }} \%\right): 295(100) \mathrm{M}^{+}$.

Pyrrole 6. ${ }^{1} \mathrm{H}$ NMR $\delta 8.28$ (br s, $\left.1 \mathrm{H}, \mathrm{NH}\right), 7.15-7.30(\mathrm{~m}, 15 \mathrm{H}, \mathrm{Ph}), 6.94\left(\mathrm{~d},{ }^{3} J_{\mathrm{H} 2, \mathrm{NH}}=3.0 \mathrm{~Hz}, 1 \mathrm{H}\right.$, $\mathrm{H}-2) ;{ }^{13} \mathrm{C}$ NMR $\delta 135.7,133.2,132.5\left(\mathrm{C}_{i}\right), 127.0-130.0\left(\mathrm{C}_{o, m}\right), 127.3(\mathrm{C}-2), 125.5-126.5\left(\mathrm{C}_{p}\right)$, 125.1 (C-4), 123.0 (C-3), 116.7 (C-5).

Pyrrole 7. ${ }^{1} \mathrm{H}$ NMR $\delta 8.41$ (br s, $\left.1 \mathrm{H}, \mathrm{NH}\right), 7.54$ (m, 2H, Ph), 7.40 (m, 6H, Ph), 7.34-7.25 (m, 5H, $\mathrm{Ph}), 7.21(\mathrm{~m}, 2 \mathrm{H}, \mathrm{Ph}), 6.73\left(\mathrm{~d},{ }^{4} J_{\mathrm{H} 4, \mathrm{NH}}=2.80 \mathrm{~Hz}, 1 \mathrm{H}, \mathrm{H}-3\right) ;{ }^{13} \mathrm{C} \mathrm{NMR} \delta 136.5,133.2\left(\mathrm{C}_{i}\right), 132.3$ $(\mathrm{C}-5), 129.4(\mathrm{C}-2), 128.4-129.1\left(\mathrm{C}_{m}\right), 127.6-128.5\left(\mathrm{C}_{o}\right), 126.0-127.1\left(\mathrm{C}_{p}\right), 124.0(\mathrm{C}-3), 123.9$ $\left(\mathrm{C}_{o}\right), 108.7$ (C-4).

2,3,4-Triphenyl-1-[(Z)-2-phenylethenyl]-1H-pyrrole (8). M.p. $146-148{ }^{\circ} \mathrm{C} ;{ }^{1} \mathrm{H}$ NMR $\delta 7.29$ (m, 4H, Ph), 7.21 (m, 7H, Ph), 7.10 (m, 5H, Ph), 7.00 (m, 4H, Ph), 6.81 (s, 1H, H-2), 6.49 (d, $\left.{ }^{3} J_{\mathrm{H} \alpha, \mathrm{H} \beta}=9.6 \mathrm{~Hz}, 1 \mathrm{H}, \mathrm{H}_{\beta}\right), 6.13\left(\mathrm{~d},{ }^{3} J_{\mathrm{H} \alpha, \mathrm{H} \beta}=9.6 \mathrm{~Hz}, 1 \mathrm{H}, \mathrm{H}_{\alpha}\right) ;{ }^{13} \mathrm{C} \mathrm{NMR} \delta 135.2,135.1,134.5\left(\mathrm{C}_{i}\right.$, $\underline{\mathrm{PhC}}=\mathrm{C}), 131.7,131.5(\mathrm{C}-2), 131.0,130.8 .128 .8\left(\mathrm{C}_{o}, \underline{\mathrm{PhC}}=\mathrm{C}\right), 128.5,128.3,127.9,127.8,127.7$ $\left(\mathrm{C}_{p}, \underline{\mathrm{PhC}}=\mathrm{C}\right), 127.2,125.8,125.6,125.5\left(\mathrm{C}_{\alpha}\right), 125.1(\mathrm{C}-4), 122.4(\mathrm{C}-3), 121.4\left(\mathrm{C}_{\beta}\right), 119.6(\mathrm{C}-5)$; IR $(\mathrm{KBr}) \vee 3064,3028,1956,1886,1814,1641,1600,1573,1530,1494,1448,1407,1391$, 1205, 1145, 1070, 1027, 954, 944, 917, 796, 775, 756, 744, 729, 695, 639, $551 \mathrm{~cm}^{-1}$. Anal. Calcd. for $\mathrm{C}_{30} \mathrm{H}_{23} \mathrm{~N}$ : C, 90.64; H, 5.83; N, 3.52. Found: C, 90.76; H, 5.62; N, 3.62.

\section{References}

1. (a) Korostova, S. E.; Mikhaleva, A. I.; Vasil'tsov, A. M.; Trofimov, B. A. Zh. Org. Khim. 1998, 34, 967. (b) Korostova, S. E.; Mikhaleva, A. I.; Vasil'tsov, A. M.; Trofimov, B. A. Zh. 
Org. Khim. 1998, 34, 1767 [Korostova, S. E.; Mikhaleva, A. I.; Vasil'tsov, A. M.; Trofimov, B. A. Russ. J. Org. Chem. 1998, 34, 911].

2. (a) Bellina, F.; Rossi, R. Tetrahedron 2006, 62, 7213. (b) Fan, H.; Peng, J.; Hamann, M. T.; Hu, J.-F. Chem. Rev. 2008, 108, 264.

3. Thompson, R. B. FASEB J. 2001, 15, 1671.

4. Zaitsev, A. B.; Meallet-Renault, R.; Schmidt, E. Yu.; Mikhaleva, A. I.; Badre, S.; Dumas, C.; Vasil'tsov, A. M.; Zorina, N. V.; Pansu, R. B. Tetrahedron 2005, 61, 2683.

5. Lee, C.-F.; Yang, L.-M.; Hwu, T.-Y.; Feng, A.-S.; Tseng, J.-C.; Luh, T.-Y. J. Am. Chem. Soc. 2000, 122, 4992.

6. Kreutzberger, A.; Kalter, P. A. J. Org. Chem. 1960, 25, 554.

7. Tedder, J. M.; Webster, B. J. Chem. Soc. 1960, 3270.

8. Sawa, Y.; Hashimoti, I.; Ryang, M.; Tsutsumi, S. J. Org. Chem. 1968, 33, 2159.

9. Overberger, C. G.; Valentine, M.; Anselme, J.-P. J. Am. Chem. Soc. 1969, 91, 687.

10. Furstner, A.; Weintritt, H; Hupperts, A. J. Org. Chem. 1995, 60, 6637.

11. Shi, D.; Shi, C.; Wang, X.; Zhuang, Q.; Tu, S.; Hu, H. Synlett 2004, 2239.

12. (a) James, D. S.; Fanta, P. E. J. Org. Chem. 1962, 27, 3346. (b) Pandey, P. S.; Rao, T. S. Bioorg. Med. Chem. Lett. 2004, 14, 129.

13. (a) Trofimov, B. A.; Mikhaleva, A. I. Khim. Geterotsikl. Soedin. 1980, 1299. (b) Trofimov, B. A.; Mikhaleva, A. I. N-Vinylpyrroles. Novosibirsk: Nauka, 1984, p 262 (in Russian). (c) Trofimov, B. A. In Nitrogen-containing heterocycles; Novosibirsk, 1987; pp 7-8 (in Russian). (d) Sobenina, L. N.; Mikhaleva, A. I.; Trofimov, B. A. Usp. Khim. 1989, 58, 275. (e) Trofimov, B. A. Usp. Khim. 1989, 58, 1703. (f) Trofimov, B. A. In Adv. Heterocycl. Chem.; Katritzky, A. R. Ed., Acad. Press: San Diego, 1990, Vol. 51; pp 177-301. (g) Trofimov, B. A. In The Synthesis, Reactivity, and Physical Properties of Substituted Pyrroles; Jones, R. A. Ed.; Wiley: New York, 1992; Vol. 48, Part II, pp 131-298.

14. (a) Trofimov, B. A.; Mikhaleva, A. I.; Korostova, S. E.; Kalabin, G. A. Khim. Geterotsikl. Soedin. 1977, 994. (b) Korostova, S. E.; Mikhaleva, A. I.; Trofimov, B. A.; Shevchenko, S. G.; Sigalov, M. V. Khim. Geterotsikl. Soedin. 1992, 485.

15. Trofimov, B. A.; Sobenina, L. N.; Petrova, O. V.; Mikhaleva, A. I. Dokl. Akad. Nauk. 1993, 328,61 .

16. Moskalev, N. V.; Timoshchenko, L. V.; Filimonov, V. D. Zh. Org. Khim. 1991, 27, 2233.

17. (a) Yurovskaya, M. A.; Afanas'ev, A. Z.; Bundel', Yu. G. Khim. Geterotsikl. Soedin. 1984, 1077. (b) Schmidt, E. Yu.; Zorina, N. V.; Zaitsev, A. B.; Mikhaleva, A. I.; Vasil'tsov, A. M.; Audebert, P.; Clavier, G.; Meallet-Renault, R.; Pansu, R. B. Tetrahedron Lett. 2004, 45, 5489. (c) Vasil’tsov, A. M.; Schmidt, E. Yu.; Mikhaleva, A. I.; Zorina, N. V.; Zaitsev, A. B.; Petrova, O. V.; Krivdin, L. B.; Petrushenko, K. B.; Ushakov, I. A.; Pozo-Conzalo, C.; Pomposo, J. A.; Grande, H.-J. Tetrahedron 2005, 61, 7756. 